\title{
Acid site densities and reactivity of oxygen- modified transition metal carbide catalysts
}

\author{
Mark M. Sullivan ${ }^{\mathrm{a}}$ and Aditya Bhan ${ }^{\mathrm{a}, *}$ \\ ${ }^{a}$ Department of Chemical Engineering and Materials Science \\ University of Minnesota - Twin Cities \\ 421 Washington Avenue SE \\ Minneapolis, Minnesota 55455 \\ $U S A$ \\ * Corresponding author. \\ E-mail addresses: sulli931@umn.edu (M. Sullivan), abhan@umn.edu (A. Bhan).
}




\begin{abstract}
Acidic properties of $\beta-\mathrm{Mo}_{2} \mathrm{C}, \alpha-\mathrm{Mo}_{2} \mathrm{C}, \mathrm{W}_{2} \mathrm{C}$, and $\mathrm{WC}$ were quantified by assessing the kinetics of isopropanol (IPA) dehydration at $415 \mathrm{~K}$ either (i) under inert $\mathrm{He} / \mathrm{Ar}$ atmosphere, or (ii) with $13 \mathrm{kPa} \mathrm{O}_{2}$ co-feed. Dehydration kinetics were zero-order with respect to IPA for all catalysts and under all reaction conditions. Intrinsic activation energies were similar across all catalysts $\left(89-104 \mathrm{~kJ} \mathrm{~mol}^{-1}\right)$. Acid site densities calculated via in situ 2,6-di-tert-butylpyridine (DTBP) titration were used to normalize dehydration turnover frequencies (TOF). $\mathrm{O}_{2}$ co-feed increased dehydration rates per gram by an order of magnitude for all catalysts tested, but TOF remained invariant within a factor of $\sim 2$. Mo and $\mathrm{W}$ based carbides showed similar dehydration kinetics regardless of $\mathrm{O}_{2}$ co-feed, and $\mathrm{O}_{2}$ co-feed did not alter bulk carbidic structure as noted by $\mathrm{X}$-ray diffraction. Brønsted acid site provenance results from the oxophilicity of Mo and W carbides.
\end{abstract}

Keywords: Brønsted acid, dehydration, molybdenum carbide, tungsten carbide, interstitial carbide, catalysis, site density, oxophilic, transition metal 


\section{Introduction}

Multifunctional interstitial transition metal carbide catalysts have been shown to catalyze hydrogenolysis, ${ }^{1-3}$ hydrogenation, ${ }^{2,4-7}$ isomerization, ${ }^{8-12}$ and hydrodeoxygenation (HDO) ${ }^{13-17}$ reactions. The diverse functionalities of transition metal carbide bulk formulations arise from different catalytically active sites generated by modification of the catalyst surface. Ribeiro et al. ${ }^{18,19}$ reported a bifunctional metal-acid surface of an oxygen-modified tungsten carbide formulation that catalyzed isomerization of $\mathrm{C}_{5}-\mathrm{C}_{7}$ alkanes at atmospheric pressure and $430-630 \quad \mathrm{~K}$ via sequential dehydrogenation/methyl shift/hydrogenation pathways as evinced by terminal isotopic enrichment in $\mathrm{n}$-heptane- $1-{ }^{13} \mathrm{C}$ isomerization reactions in contrast to the $\mathrm{C}_{5}$ hydrogenolysis mechanism prevalent over noble metals that would also yield isotopic enrichment of interior carbon atoms. $\mathrm{WC}$ and $\mathrm{W}_{2} \mathrm{C}$ catalysts were oxygen-modified via slow $\mathrm{O}_{2}$ introduction $\left(0.1 \mu \mathrm{mol} \mathrm{s} \mathrm{g}^{-1}\right)$ at room temperature followed by heating under 20 $\mathrm{kPa} \mathrm{O}_{2}$ to $300-800 \mathrm{~K}$, and catalysts were finally pretreated under $\mathrm{H}_{2}$ flow at $673 \mathrm{~K}$ for 1-2 $\mathrm{h}$ prior to exposure to reaction conditions $\left(95 \mathrm{kPa} \mathrm{H}_{2}\right)$. The presence of Brønsted acid sites on $\mathrm{O}^{*}-\mathrm{WC}_{\mathrm{x}}$ catalysts was implicated by the methyl shift isomerization mechanism in addition to ex situ $\mathrm{NH}_{3}$ temperature programmed desorption (TPD) studies; these acid sites were shown to be similar to acid sites on $\mathrm{WO}_{\mathrm{x}}$ catalysts because comparable product distributions of 3,3-dimethylpentane isomerization over $\mathrm{O}$ - WC and $\mathrm{Al}_{2} \mathrm{O}_{3}$-supported $\mathrm{Pt} / \mathrm{WO}_{3}$ catalysts were observed. Isomerization site time yields, normalized by ex situ irreversible $\mathrm{CO}$ chemisorption uptakes, were similar over $700-\mathrm{K}$ oxygen-modified WC and $\mathrm{W}_{2} \mathrm{C}$ catalysts $\left(244 \times 10^{-3}\right.$ vs. $\left.125 \times 10^{-3} \mathrm{~s}^{-1}\right) \cdot{ }^{8,18,19}$ Lamic and coworkers ${ }^{20}$ also demonstrated isomerization of $\mathrm{n}$-heptane over both bifunctional $\mathrm{WC}_{\mathrm{x}}$ and mixed 
$\mathrm{Mo}_{2} \mathrm{C} / \mathrm{WO}_{2}$ catalysts, hypothesizing that the carbidic $\mathrm{Mo}_{2} \mathrm{C}$ or $\mathrm{WC}_{\mathrm{x}}$ acts as the de/hydrogenation catalyst and the acidic $\mathrm{WO}_{2}$ provides the Brønsted acidic site necessary for the isomerization of $n$-heptene via a carbenium ion intermediate.

Iglesia and coworkers ${ }^{21,22}$ demonstrated the presence of both Brønsted and Lewis acid sites on supported $\mathrm{WO}_{\mathrm{x}}$ catalysts that were active for both isomerization and dehydration through the use of in situ pyridine and 2,6-di-tert-butylpyridine (DTBP) titrations. Ruddy and coworkers ${ }^{23,24}$ demonstrated the presence of acid sites on bulk $\beta$ $\mathrm{Mo}_{2} \mathrm{C}$ and on SBA-15-supported $\alpha-\mathrm{MoC}_{1-\mathrm{x}}$ nanoparticles via both $\mathrm{NH}_{3}$ temperature programmed desorption (TPD) studies and density functional theory (DFT) calculations that showed comparable $\mathrm{NH}_{3}$ binding energies between $\mathrm{O}^{*}-\mathrm{MoC}_{\mathrm{x}}$ and proton-form zeolites. Although acid sites have been reported to exist across transition metal oxides and oxygen-modified transition metal carbides, quantification and comparison of acid site densities and strengths are lacking, and similarities between oxidic and carbidic acid sites have yet to be characterized.

We have previously investigated the acidic and metallic characteristics of molybdenum carbide catalytic formulations during HDO of biomass-derived oxygencontaining molecules including anisole, furfural, m-cresol, and acetone. ${ }^{25-31}$ Metallic sites responsible for anisole, furfural, and m-cresol HDO can be selectively titrated using $\mathrm{CO}$, and Brønsted acid sites responsible for the rate-determining isopropanol (IPA) dehydration during the sequential hydrogenation/dehydration of acetone could be selectively titrated using DTBP. These in situ titrations allow for site density and TOF measurements of the catalytically active sites without ex situ methods, yielding both the identity and quantity of active sites. 
In this work, we use IPA dehydration activation energy, TOF, and site density measurements as probes of acid sites on freshly synthesized as well as oxygen-modified $\left(\mathrm{O}^{*}\right)$ transition metal carbide catalysts of molybdenum and tungsten $\left(\alpha-\mathrm{Mo}_{2} \mathrm{C}, \beta-\mathrm{Mo}_{2} \mathrm{C}\right.$, $\mathrm{W}_{2} \mathrm{C}$, and $\mathrm{WC}$ ). Catalysts demonstrated extreme oxophilicity as noted by zero-order kinetics with respect to IPA pressure, indicative of a catalyst surface saturated with oxygenate. Intrinsic activation energies and dehydration turnover frequencies (TOF) were calculated using acid site densities measured via in situ DTBP titration. Selective DTBP titration both directly demonstrates the presence of Brønsted acid sites on $\mathrm{O}^{*}$-modified carbides and allows for calculation of intrinsic dehydration TOF values. Acid site densities increased with $\mathrm{O}_{2}$ co-feed-induced surface oxidation, but the nature of the active sites, as quantified via intrinsic activation energies and TOF, was similar across all measured catalysts regardless of bulk carbide structure, presence of $\mathrm{O}_{2}$ co-feed, or bulk transition metal (Mo or W). The nature of the acid sites on TPR-synthesized transition metal carbides is uniform across formulations oxidized by both reactant alcohol O* incorporation and direct $\mathrm{O}_{2}$ co-feed at reaction conditions. The persistent and consistent nature of acid site identity with $\mathrm{O}^{*}$ source, site density, transition metal, and bulk crystal structure serves to further the understanding of catalytic applications of oxophilic transition metal carbides or other oxophilic catalytic materials from both a fundamental perspective as well as for any potential acid catalysis/HDO applications.

\section{Experimental}

\subsection{Catalyst synthesis and passivation}


All catalysts were prepared in a quartz tubular reactor (I.D. $10 \mathrm{~mm}$ ). Catalyst precursors were heated either in a three-zone or in a one-zone split tube furnace (Applied Test Systems) under gas flows including $\mathrm{CH}_{4}$ (Matheson, 99.97\%), $\mathrm{H}_{2}$ (Matheson, 99.999\%), or He (Minneapolis Oxygen, 99.997\%).

Synthesis of orthorhombic $\beta-\mathrm{Mo}_{2} \mathrm{C}$ was carried out using a temperatureprogrammed reaction method reported previously. ${ }^{25,32,33}$ Batches of catalyst were synthesized using $0.03-1.0 \mathrm{~g}$ ammonium paramolybdate (sieved, 177-400 $\mu \mathrm{m}$, $\left(\mathrm{NH}_{4}\right)_{6} \mathrm{Mo}_{7} \mathrm{O}_{24} \bullet 4 \mathrm{H}_{2} \mathrm{O}$, Sigma, $99.98 \%$, trace metal basis). The paramolybdate was heated at $0.06 \mathrm{~K} \mathrm{~s}^{-1}$ to $623 \mathrm{~K}$ and held at $623 \mathrm{~K}$ for $12 \mathrm{~h}$ under total flow of $3.0 \mathrm{~cm}^{3} \mathrm{~s}^{-1}$ of 15 vol\% $\mathrm{CH}_{4} / \mathrm{H}_{2}$, followed by a temperature ramp at $0.046 \mathrm{~K} \mathrm{~s}^{-1}$ from $623 \mathrm{~K}$ to $873 \mathrm{~K}$ and a temperature hold at $873 \mathrm{~K}$ for $2 \mathrm{~h}$. The reactor was then cooled under the same gas flow to reaction temperature $(415 \mathrm{~K})$ to begin reaction.

Cubic $\alpha-\mathrm{Mo}_{2} \mathrm{C}$ (also labeled as $\left.\alpha-\mathrm{MoC}_{1-\mathrm{x}}\right)^{24}$ was synthesized according to a modified method of Vitale and coworkers. ${ }^{34}$ Sucrose $(5 \mathrm{~g})$ and ammonium paramolybdate (5 g) were dissolved in $40 \mathrm{~mL}$ deionized $\mathrm{H}_{2} \mathrm{O}$, and the mixture was homogenized and magnetically stirred at ambient temperature for $0.25 \mathrm{~h}$. The mixture was then placed in an oven at $393 \mathrm{~K}$ for $24 \mathrm{~h}$. A dark grey porous solid mass was formed; the resulting solid was crushed and used as a precursor. Approximately $2 \mathrm{~g}$ of this precursor was treated under flowing He, heated at $0.25 \mathrm{~K} \mathrm{~s}^{-1}$ to $1073 \mathrm{~K}$, held at $1073 \mathrm{~K}$ for $0.5 \mathrm{~h}$, then cooled to ambient temperature under the same flow. This product was shown to have bulk $\alpha-\mathrm{Mo}_{2} \mathrm{C}$ crystal structure (see discussion in Section 3 below). Approximately $0.2 \mathrm{~g}$ of this precursor was then heated under flowing He to $415 \mathrm{~K}$ for IPA dehydration measurements 
and was subsequently treated with $13 \mathrm{kPa} \mathrm{O}_{2}$ co-feed under reaction conditions as dehydration rates rose until they reached a stable value.

$\mathrm{WC}$ and $\mathrm{W}_{2} \mathrm{C}$ catalysts were synthesized according to a modified method of Delannoy and coworkers. ${ }^{35}$ Both catalysts were synthesized with $0.03-0.1 \mathrm{~g} \mathrm{WO}_{3}$ precursor (Sigma Aldrich, $99.995 \%$ trace metal basis) using the quartz tube flow system described above under $1.82 \mathrm{~cm}^{3} \mathrm{~s}^{-1}$ total flow of $20 \% \mathrm{CH}_{4} / \mathrm{H}_{2}$ and heated at $0.0167 \mathrm{~K} \mathrm{~s}^{-1}$ until their final synthesis temperature (1073 K for $\mathrm{WC}, 903$ for $\mathrm{W}_{2} \mathrm{C}$ ), and finally held isothermally for $8 \mathrm{~h} . \mathrm{CH}_{4}$ gas flow was then removed, and the catalyst was allowed to cool to $415 \mathrm{~K}$ under $\mathrm{H}_{2}$ flow.

Catalysts were passivated after reaction by treatment in flowing $1 \% \quad \mathrm{O}_{2} / \mathrm{He}$ (Matheson, Certified Standard Purity) at $1.0 \mathrm{~cm}^{3} \mathrm{~s}^{-1}$ for at least $0.75 \mathrm{~h}$ in an effort to

avoid violent bulk oxidation with atmospheric $\mathrm{O}_{2} \cdot{ }^{36,37}$ Samples were passivated even if treated with $\mathrm{O}_{2}$ co-feed during reaction.

\subsection{Catalyst characterization}

The mass fraction of molybdenum in the $\alpha-\mathrm{Mo}_{2} \mathrm{C}$ was analyzed by inductively coupled plasma optical emission spectroscopy (ICP-OES); experimental details are provided in Section S.1 of Supplementary Information.

X-ray diffraction (XRD) was performed with a Bruker D8 Discover 2D X-ray diffractometer equipped with a 2-D VÅNTEC-500 detector and a 0.8-mm collimator. $\mathrm{Cu}$ $\mathrm{K}_{\alpha 1}$ and $\mathrm{K}_{\alpha 2}$ radiation was used in conjunction with a graphite monochromator. Scans were performed in two or three frames for $300 \mathrm{~s}$ per frame. Total scan range was typically $2 \theta=20^{\circ}$ to $80^{\circ}$ with the scan frames being adjusted so as to center the primary intensity peaks in each frame. The $2 \mathrm{D}$ scans were converted to $1 \mathrm{D}$ intensity vs. $2 \theta$ with a 
step size of $0.04^{\circ} 2 \theta$ and merged for analysis. A zero background holder was used with a small amount of vacuum grease for sample support.

Surface area and porosity of the passivated catalyst samples was measured using an ASAP Micromeritics 2020 analyzer. BET surface area and porosity measurements using $\mathrm{N}_{2}$ were performed at liquid nitrogen boiling temperature. Prior to $\mathrm{N}_{2}$ physisorption measurements, samples were degassed to $<6 \mu \mathrm{m} \mathrm{Hg}$ and heated to $523 \mathrm{~K}$ at $0.17 \mathrm{~K} \mathrm{~s}^{-1}$ and held for 2-4 h. BET Surface areas of oxygen-modified carbide samples were typically $<5 \mathrm{~m}^{2} \mathrm{~g}^{-1}$, and surface areas of post-reaction samples without $\mathrm{O}_{2}$ co-feed were typically $\sim 20-60 \mathrm{~m}^{2} \mathrm{~g}^{-1}$; surface areas were not used for quantitative comparison due to their evolution with $\mathrm{O}_{2}$ exposure ${ }^{38}$ or aging time. ${ }^{28}$

\subsection{Reaction and titration methods}

Reactions were carried out in an apparatus described previously. ${ }^{32}$ Briefly, reactants were fed to stainless steel reactor lines via either an M6 Valco syringe-free liquid handling pump or a KD Scientific syringe pump (KDS120). Reactant lines were heated by resistive heating tape to prevent condensation. 2-Propanol (ACS 99.97\%), argon (Matheson, 99.999\%), and helium (Minneapolis Oxygen, 99.997\%) were used as received. Products and reactants at the reactor effluent were quantified using a flame ionization detector (FID) with an online gas chromatograph (Agilent 7890 GC); gasphase separation prior to the FID was accomplished with a J\&W HP-1 dimethylpolysiloxane column (50.0 m length, $320 \mu \mathrm{m}$ I.D., $0.52 \mu \mathrm{m}$ film). Helium was used as the column carrier gas at a flow rate of $0.15 \mathrm{~cm}^{3} \mathrm{~s}^{-1}$. GC oven temperature profiles for reactor effluent separation typically began at $213 \mathrm{~K}$ for $0.058 \mathrm{~h}$ and were ramped to $423 \mathrm{~K}$ at $0.42 \mathrm{~K} \mathrm{~s}^{-1}$. 
IPA partial pressure was varied from $\sim 0.044-4.4 \mathrm{kPa}$ by altering liquid flow rates from $\sim 10$ to $800 \mu \mathrm{L} \mathrm{h}^{-1}$. For temperature variation experiments, reactor temperature was measured at the moment of sample injection into the GC with reactor temperature measured by a thermocouple in a thermal well on the external surface of the quartz reactor. Temperatures were raised and lowered $\sim 15 \mathrm{~K}$ from the standard reaction temperature of $415 \mathrm{~K}$; repeats of rates at multiple temperatures were performed over the course of the experiment to ensure consistency and lack of catalyst history effects.

Titration experiments were performed with liquid mixtures of IPA and 2,6-di-tertbutylpyridine (DTBP). After catalyst synthesis and possible $\mathrm{O}_{2}$ co-feed introduction, IPA was introduced and steady state propylene production rates were obtained (typically $\sim 1 \mathrm{~h}$ of stabilization time). IPA partial pressure variation experiments were performed first, followed by temperature variation experiments. Temperature and propylene production rates were subsequently stabilized at $415 \mathrm{~K}$. The flow of reactants was then switched from pure IPA flow to the IPA/DTBP mixture at an identical volumetric flow rate. DTBP mole fraction in the IPA/DTBP mixture was $\sim 3 \times 10^{-4}$. The propylene formation rate was monitored using online gas chromatography and was linearly extrapolated to zero during titration to estimate the total DTBP uptake as a measure of acid site density.

\section{Results and Discussion}

Figure 1 (a) shows the rate of IPA dehydration to form propylene over in situ synthesized molybdenum and tungsten carbides without any exposure to oxygen. Rates are normalized by the total moles of metal atoms in the oxide precursor. Rates were measured in the absence of heat and mass transfer limitations (Section S.2 of 
Supplementary Information). Dehydration rates typically varied $<10 \%$ over the course of a $\sim 8 \mathrm{~h}$ experiment to measure IPA pressure dependence, activation energy, and TOF. Fresh carbides that had not been exposed to $\mathrm{O}_{2}$ co-feed exhibited increasing dehydration rates at early times on stream, hypothesized to be attributable to surface oxidation from deposited oxygen during an initial transient in IPA catalytic dehydration. Propylene formation rates over all carbides exhibit zero-order dependence upon IPA pressure over two orders of magnitude $(\sim 0.044-4.4 \mathrm{kPa})$. The zero-order dependence is in line with the expected oxophilicity of these carbides; the catalyst surface is saturated with IPA even at low reactant partial pressures. Propylene was the primary product formed. Acetone was formed in small quantities ( $<5 \%$ carbon selectivity) over fresh catalysts and formed negligibly once $\mathrm{O}_{2}$ co-feed was introduced. Di-isopropylether (DIPE) was formed with typically $<10 \%$ carbon selectivity. DIPE formation rates showed a positive order dependence upon IPA pressure. DIPE formation rates were not used for characterization and quantification of acid sites on the catalyst in this study due to the non-zero order kinetics and the low product formation rates. A linear dependence of carbon conversion on contact time evinced an absence of product inhibition. ${ }^{32}$

Carbides synthesized under identical conditions were also tested for IPA dehydration with a co-feed of $13 \mathrm{kPa} \mathrm{O}_{2}$, and the results are plotted in Figure 1(b). $\mathrm{O}_{2}$ cofeed increased dehydration rates per bulk metal atom by an order of magnitude for all carbides tested in this work. The rate dependence upon IPA pressure remained invariant (zero-order), indicative of a reactant-saturated surface. These results for $\beta-\mathrm{Mo}_{2} \mathrm{C}$ have been published previously, ${ }^{32}$ and the three additional carbides tested in this work behaved 
similarly as characterized by zero-order kinetics and a concurrent increased dehydration rate with $\mathrm{O}_{2}$-induced surface oxidation.

Temperature variation experiments were performed on carbides with both zero and $13 \mathrm{kPa} \mathrm{O}_{2}$ co-feed, and the rates of propylene formation as a function of temperature are plotted in Figures 2(a) and 2(b). The activation energies that can be extracted from the slopes of Figures 2(a) and 2(b) are intrinsic because of the zero-order dehydration kinetics. The data presented in Figures 1(a) and 1(b) exhibit an order of magnitude increase in the measured propylene rates with oxygen co-feed, but the IPA dehydration kinetics (as quantified by the activation energy) remained invariant even with an order of magnitude increase in rate. The activation energies extracted from the slopes of Figures 2(a) and 2(b) and tabulated in Table 1 are shown to be similar.

Propylene turnover frequencies (TOF), normalized by the acid site density calculated from the extrapolated time to complete titration based off of DTBP co-feed titration experiments, are plotted in Figure 3 and also tabulated in Table 1. Acid site densities per bulk metal atom are also reported due to difficulties in accurately ascertaining oxidized sample surface area as mentioned in Section 2.2. A typical DTBP titration experiment is shown in Section S.3 of Supplementary Information. TOF values for all experiments performed in this work are plotted in Figure 3 along with TOF values calculated from intermediate $\mathrm{O}_{2}$ co-feed pressures for $\mathrm{W}_{2} \mathrm{C}$ and $\beta-\mathrm{Mo}_{2} \mathrm{C}$. A TOF for $\alpha-$ $\mathrm{Mo}_{2} \mathrm{C}$ with no $\mathrm{O}_{2}$ co-feed could not be calculated due to the inability of DTBP to titrate the extremely low dehydration rate. The nature of the as-synthesized $\alpha-\mathrm{Mo}_{2} \mathrm{C}$ surface was noticeably different from the other catalysts used in this study due to the synthesis procedure (described in the experimental section). The surface prior to $\mathrm{O}_{2}$ co-feed was 
expected to be covered in carbon residue due to the large carbon content of the sucrose in the synthesis precursor. ICP-OES of the $\alpha-\mathrm{Mo}_{2} \mathrm{C}$ sample showed $\sim 37 \mathrm{wt} \%$ Mo as compared to the theoretical $94 \mathrm{wt} \%$ Mo of a pure $\alpha-\mathrm{Mo}_{2} \mathrm{C}$ sample. $\mathrm{O}_{2}$ co-feed caused a $\sim 130 \mathrm{~h}$ transient during which the propylene production rate rose and finally stabilized; IPA dehydration pressure dependence, activation energy, and TOF were measured at this stable dehydration rate (Section S.4 of Supplementary Information).

Propylene TOF values for all $\mathrm{MoC}_{\mathrm{x}}$ samples varied within a factor of $\sim 2$ regardless of $\mathrm{O}_{2}$ co-feed pressure; $\mathrm{WC}_{\mathrm{x}}$ propylene TOF values also varied within a factor of $\sim 2$ for $\mathrm{O}_{2}$ co-feed experiments. $\mathrm{WC}_{\mathrm{x}}$ propylene $\mathrm{TOF}$ values were also typically higher than $\mathrm{MoC}_{\mathrm{x}}$ by a factor of $\sim 2$. This implicates a similarity in the nature of the acid sites for IPA dehydration across fresh and oxygen modified carbides of molybdenum and tungsten.

Propylene rates were not entirely inhibited by DTBP co-feed; DTBP was able to irreversibly titrate $85-94 \%$ of the dehydration rates of O*-carbides, but DTBP could only titrate $40-50 \%$ of the dehydration rate of fresh carbides that had never been exposed to $\mathrm{O}_{2}$. This could be explained by the presence of acid sites that DTBP cannot chemically bind to, such as (i) Lewis acid sites, and/or (ii) sites that are sterically inaccessible to DTBP either due to the presence of catalyst pores on the order of 1-2 nm for $\beta-\mathrm{Mo}_{2} \mathrm{C}^{32}$ or due to closely localized acid sites (crystal edge sites). The propylene TOF was calculated by assuming that all sites are chemically identical Brønsted acid sites. The presence of Lewis acid sites or a non-uniform distribution of sites would cause a distribution in TOF values that is not captured in this single-value TOF estimation technique and would also account for the un-titrated rate; we are unable to distinguish 
between the relative effects of possible Lewis acid sites or sterically inaccessible sites. However, the measured similarity in reaction order dependences, activation energies, and turnover frequencies across all catalyst samples implies the lack of a broad spectrum of active sites with varying reactivity.

The post-reaction X-ray diffraction patterns of all catalysts tested for IPA dehydration in Figures 1, 2, and 3 are presented in Figure 4. Figure 4 shows that the bulk structures of $\mathrm{WC}, \mathrm{W}_{2} \mathrm{C}$, and $\alpha-\mathrm{Mo}_{2} \mathrm{C}$ were unaffected by $\mathrm{O}_{2}$ co-feed at $415 \mathrm{~K}$ under reaction conditions. Transition metal carbide catalysts demonstrate Brønsted acidity due to surface oxidation, and the acid sites generated are similar regardless of the extent of oxidation or bulk transition metal composition as evinced by similar kinetics and propylene TOF values. Surface oxidation increases surface acid site density, but bulk carbide crystal structure remains unchanged with $\mathrm{O}_{2}$-induced surface alterations.

The IPA dehydration kinetic parameters as reported in Table 1 are relatively independent of bulk carbidic crystal structure, implying that (i) the structure and composition of the bulk carbide minimally alter the acidic properties of the catalyst surface, and (ii) oxygen modification with $\mathrm{O}_{2}$ co-feed increased the number of acidic active sites without significantly altering the nature of the acid sites. XPS of carbide catalysts after $13 \mathrm{kPa}$ of $\mathrm{O}_{2}$ co-feed for over $12 \mathrm{~h}$ showed no transition metal in the carbidic oxidation state $\left(<10\right.$ atom $\left.\% \mathrm{Mo}^{3+}\right)$ with the bulk of the surface atoms residing as oxides or suboxides $\left(\mathrm{Mo}^{5+}\right.$ and $\left.\mathrm{Mo}^{6+}\right)$ as shown in Section S.5 of Supplementary Information. This increase in surface oxidation with concurrent increase in acidic active site density as measured by in situ titrations suggests that the Brønsted acid sites on the 
carbide surfaces, both fresh and oxygen modified, are similar in nature to acid sites present on transition metal oxides.

While both fresh and oxygen-modified $\mathrm{MoC}_{\mathrm{x}}$ and $\mathrm{WC}_{\mathrm{x}}$ catalyze IPA dehydration at nearly identical rates, it is worth noting the effects of different oxophilicities of the $\mathrm{MoC}_{\mathrm{x}}$ and $\mathrm{WC}_{\mathrm{x}}$ catalysts shown by the effects of $\mathrm{O}_{2}$ co-feed pressure in Figure 3. An increase from $0.3 \mathrm{kPa}$ to $13.5 \mathrm{kPa} \mathrm{O}$ co-feed over $\beta-\mathrm{Mo}_{2} \mathrm{C}$ did not affect the dehydration TOF ( 0.16 vs. $\left.0.13 \mathrm{~s}^{-1}\right)$, but the acid site density was nearly doubled as noted by the dehydration rate per Mo atom (45 vs. $84 \mathrm{~mol} \mathrm{~s}^{-1} \mathrm{~mol}_{\mathrm{Mo}^{-1}}$ ). Conversely, $\mathrm{O}_{2}$ co-feed of 0.4 $\mathrm{kPa}$ and $13 \mathrm{kPa}$ over $\mathrm{W}_{2} \mathrm{C}$ induced nearly identical TOF values $\left(0.3\right.$ vs. $\left.0.31 \mathrm{~s}^{-1}\right)$ as well as acid site densities (rates of 241 vs. $241 \mathrm{~mol} \mathrm{~s}^{-1} \mathrm{~mol}_{\mathrm{W}}^{-1}$ ). Dehydration rates over $\beta$ $\mathrm{Mo}_{2} \mathrm{C}$ increased gradually over the range of $\mathrm{O}_{2}$ co-feed pressures from $0-13 \mathrm{kPa}$ with $\mathrm{O}_{2}$ pressures above $\sim 10 \mathrm{kPa}$ not affecting the dehydration rate. Conversely, $\mathrm{O}_{2}$ co-feed of $0.4 \mathrm{kPa}$ over $\mathrm{W}_{2} \mathrm{C}$ induced a maximum dehydration rate, and higher $\mathrm{O}_{2}$ co-feed pressures caused no additional increase in the dehydration rates as noted in Figure 3 and in Section S.6 of Supplementary Information. DeMaria et al. ${ }^{39}$ used a Knudsen cell in conjunction with mass spectroscopic methods to correlate partial pressures of vaporized metal oxides to enthalpies of metal-oxygen bond formation; the greater comparative oxophilicity of tungsten with respect to molybdenum is evident from the enthalpies of formation of Mo$\mathrm{O}$ and $\mathrm{W}-\mathrm{O}$ bonds (485 \pm 63 and $644 \pm 42 \mathrm{~kJ} \mathrm{~mol}^{-1}$, respectively). Oxygen co-feed over both $\mathrm{MoC}_{\mathrm{x}}$ and $\mathrm{WC}_{\mathrm{x}}$ catalysts generates Brønsted acid sites due to the oxophilicity of these formulations, and the acid sites generated on the catalyst surface saturate with increasing $\mathrm{O}_{2}$ pressure, but the greater oxophilicity of $\mathrm{WC}_{\mathrm{x}}$ in comparison to $\mathrm{MoC}_{\mathrm{x}}$ catalysts causes the maximum acid site density to saturate at lower $\mathrm{O}_{2}$ co-feed pressure. 


\section{Conclusions}

Carbides of molybdenum and tungsten exhibit Brønsted acidity following carbide synthesis without exposure to $\mathrm{O}_{2}$ as evinced by irreversible DTBP titration. Dioxygen cofeed increases the rate of acidic dehydration of IPA to propylene at $415 \mathrm{~K}$ by an order of magnitude over interstitial carbides of molybdenum and tungsten; $\mathrm{O}_{2}$-induced surface oxidation does not alter the bulk carbide structures as evidenced by the unchanged postreaction X-ray diffraction patterns. The oxophilic characteristics of fresh and $\mathrm{O}_{2}$ modified $\left(\mathrm{O}^{*}\right)$ carbides result in IPA surface saturation with partial pressures as low as $0.044 \mathrm{kPa}$ and in zero-order dehydration kinetics to propylene. Intrinsic activation energies of unimolecular dehydration over fresh and $\mathrm{O}^{*}$-modified carbides were similar $\left(89-104 \mathrm{~kJ} \mathrm{~mol}^{-1}\right)$ across carbide bulk structure, with or without $\mathrm{O}_{2}$ co-feed. Propylene TOF values for fresh and $\mathrm{O}^{*}$-carbides, normalized by the calculated Brønsted acid site density obtained from extrapolation of DTBP rates of titration, were similar within a factor of $\sim 2$ for both molybdenum and tungsten carbides. The oxophilicity of the transition metal carbide formulations results in the concurrent genesis of Brønsted acidity with catalyst surface oxidation without the alteration of bulk crystal structure.

\section{Acknowledgements}

This research was supported by Office of Basic Energy Sciences, the U.S. Department of Energy under award number no. DE- SC0008418 (DOE Early Career Program). Part of this work was carried out in the College of Science and Engineering Characterization Facility, University of Minnesota, which has received capital equipment funding from the 
NSF through the MRSEC program. We thank Javier Garcia Barriocanal for assistance with the X-ray diffraction studies, Rick Knurr for assistance with the ICP-OES characterization, and Bing Luo for assistance with the XPS characterization. 


\section{References}

1 J. S. Lee, S. Locatelli, S. T. Oyama and M. Boudart, J. Catal., 1990, 125, 157-170.

2 G. S. Ranhotra, A. T. Bell and J. A. Reimer, J. Catal., 1987, 108, 40-49.

3 J. H. Sinfelt and D. J. C. Yates, Nat. Phys. Sci., 1971, 229, 27-28.

4 J.-S. S. Choi, G. Bugli and G. Djéga-Mariadassou, J. Catal., 2000, 193, 238-247.

5 H. Shou and R. J. Davis, J. Catal., 2013, 306, 91-99.

6 M.-L. Frauwallner, F. López-Linares, J. Lara-Romero, C. E. Scott, V. Ali, E. Hernández and P. Pereira-Almao, Appl. Catal. A Gen., 2011, 394, 62-70.

7 K. J. Leary, J. N. Michaels and M. Stacy, J. Catal., 1986, 101, 301-313.

8 E. Iglesia, J. E. Baumgartner, F. H. Ribeiro and M. Boudart, J. Catal., 1991, 131, 523-544.

9 A. F. Lamic, C. H. Shin, G. Djéga-Mariadassou and C. Potvin, Appl. Catal. A Gen., 2006, 302, 5-13.

10 E. A. Blekkan, C. Pham-Huu, M. J. Ledoux and J. Guille, Ind. Eng. Chem. Res., 1994, 33, 1657-1664.

11 R. B. Levy and M. Boudart, Science (80-. )., 1973, 181, 547-549.

12 V. Keller, P. Wehrer, F. Garin, R. Ducros and G. Maire, J. Catal., 1997, 166, 125135.

13 H. Ren, W. Yu, M. Salciccioli, Y. Chen, Y. Huang, K. Xiong, D. G. Vlachos and J. G. Chen, ChemSusChem, 2013, 6, 798-801.

14 H. Ren, Y. Chen, Y. Huang, W. Deng, D. G. Vlachos and J. G. Chen, Green Chem., 2014, 16, 761-769.

15 K. Xiong, W. Yu, D. G. Vlachos and J. G. Chen, ChemCatChem, 2015, 7, 14021421.

16 A. L. Jongerius, R. W. Gosselink, J. Dijkstra, J. H. Bitter, P. C. A. Bruijnincx and B. M. Weckhuysen, ChemCatChem, 2013, 5, 2964-2972.

17 S. Boullosa-Eiras, R. Lødeng, H. Bergem, M. Stöcker, L. Hannevold and E. A. Blekkan, Catal. Today, 2014, 223, 44-53.

18 F. H. Ribeiro, R. a. Dalla Betta, M. Boudart, J. E. Baumgartner and E. Iglesia, J. Catal., 1991, 130, 86-105.

19 F. H. Ribeiro, M. Boudart, R. A. D. Betta, R. A. Dalla Betta and E. Iglesia, J. Catal., 1991, 513, 498-513.

20 A. F. Lamic, T. L. H. Pham, C. Potvin, J. M. Manoli and G. Djéga-Mariadassou, J. Mol. Catal. A Chem., 2005, 237, 109-114.

21 J. Macht, C. D. Baertsch, M. May-Lozano, S. L. Soled, Y. Wang and E. Iglesia, J. Catal., 2004, 227, 479-491.

22 C. Baertsch, K. T. Komala, Y. Chua and E. Iglesia, J. Catal., 2002, 205, 44-57.

23 J. A. Schaidle, J. Blackburn, C. A. Farberow, C. Nash, K. X. Steirer, J. Clark, D. J. Robichaud and D. A. Ruddy, ACS Catal., 2016, 6, 1181-1197.

24 F. G. Baddour, C. P. Nash, J. A. Schaidle and D. A. Ruddy, Angew. Chemie Int. Ed., 2016, 55, 1-5.

25 W. Lee, Z. Wang, R. Wu and A. Bhan, J. Catal., 2014, 319, 44-53.

26 C.-J. Chen, W.-S. Lee and A. Bhan, Appl. Catal. A Gen., 2015, 510, 42-48.

27 M. M. Sullivan and A. Bhan, ACS Catal., 2016, 6, 1145-1152.

28 W.-S. Lee, Z. Wang, W. Zheng, D. G. Vlachos and A. Bhan, Catal. Sci. Technol., 
2014, 4, 2340-2352.

29 K. Xiong, W.-S. Lee, A. Bhan and J. G. Chen, ChemSusChem, 2014, 7, 21462149.

30 W.-S. Lee, A. Kumar, Z. Wang and A. Bhan, ACS Catal., 2015, 2, 4104-4114.

31 M. M. Sullivan, C.-J. C.-J. Chen and A. Bhan, Catal. Sci. Technol., 2016, 6, 602616.

32 M. M. Sullivan, J. T. J. T. Held and A. Bhan, J. Catal., 2015, 326, 82-91.

33 J. A. Schaidle, N. M. Schweitzer, O. T. Ajenifujah and L. T. Thompson, J. Catal., 2012, 289, 210-217.

34 G. Vitale, M. L. Frauwallner, C. E. Scott and P. Pereira-Almao, Appl. Catal. A Gen., 2011, 408, 178-186.

35 L. Delannoy, J.-M. Giraudon, P. Granger, L. Leclercq and G. Leclercq, Catal. Today, 2000, 59, 231-240.

36 J. S. Lee, S. T. Oyama and M. Boudart, J. Catal., 1987, 106, 125-133.

37 S. K. Bej and L. T. Thompson, Appl. Catal. A Gen., 2004, 264, 141-150.

38 M. M. Sullivan and A. Bhan, ACS Catal., 2016, 6, 1145-1152.

39 G. De Maria, R. P. Burns, J. Drowart and M. G. Inghram, J. Chem. Phys., 1960, 32, 1373. 
a)

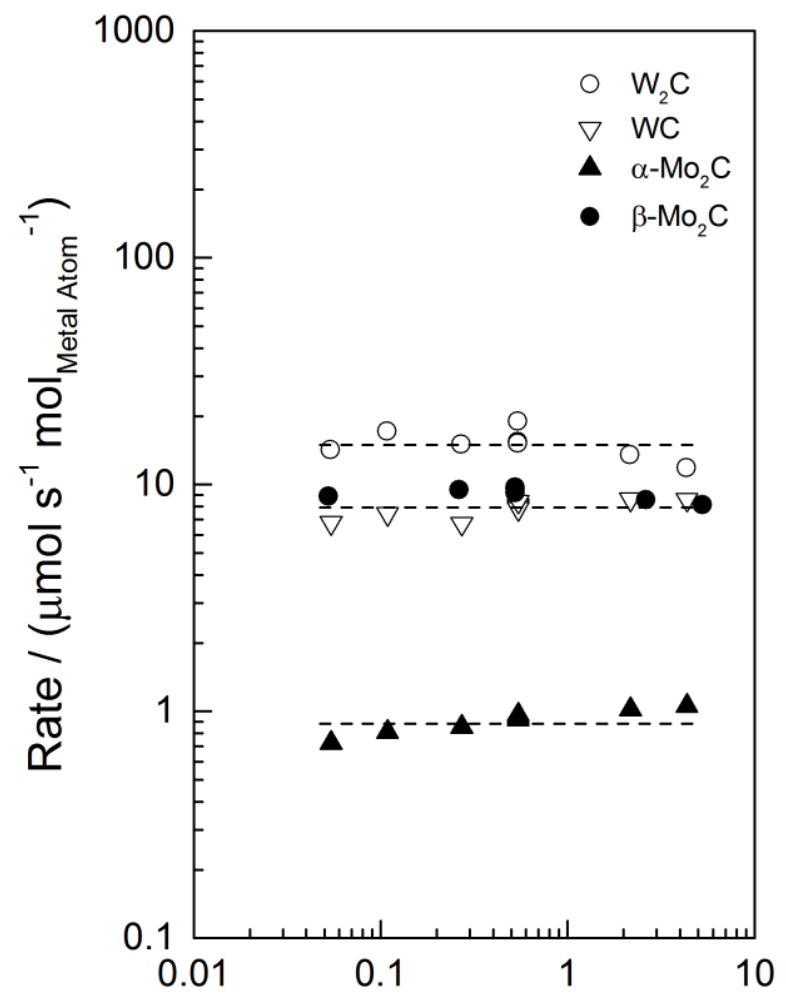

b)

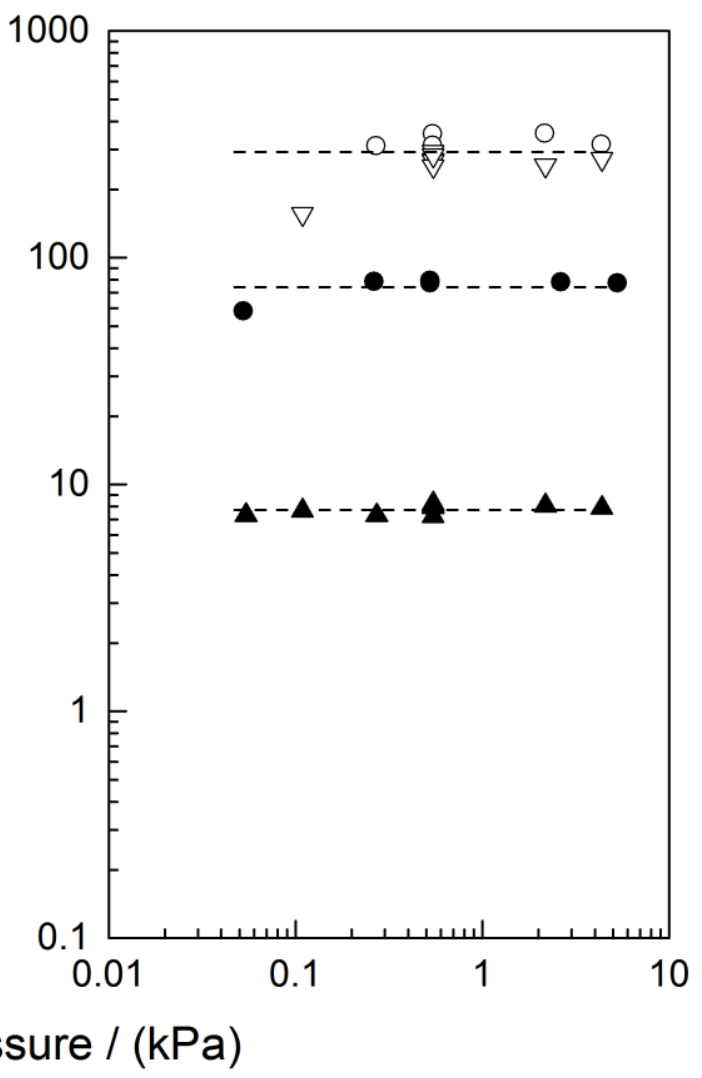

Figure 1. Propylene synthesis rates over interstitial carbide catalysts of tungsten and molybdenum, normalized per mole of $\mathrm{W}$ or Mo, as a function of IPA partial pressure (a) with no $\mathrm{O}_{2}$ co-feed, or (b) with $13 \mathrm{kPa} \mathrm{O}_{2}$ co-feed. $\mathrm{T}=415 \mathrm{~K}, \mathrm{P}=114 \mathrm{kPa}, \mathrm{P}_{\mathrm{CH} 4}=4 \mathrm{kPa}$ (internal standard), balance He or Ar. Total gas flow rate of $1.83 \mathrm{~cm}^{3} \mathrm{~s}^{-1}$. Approximately $0.1 \mathrm{~g}$ of oxide precursor was loaded for each synthesis and subsequent reaction tests $(0.2$ $\mathrm{g}$ for $\alpha-\mathrm{Mo}_{2} \mathrm{C}$ ). Conversion varied from $0.1-19 \%$ for (a) and $0.3-66 \%$ for (b). 


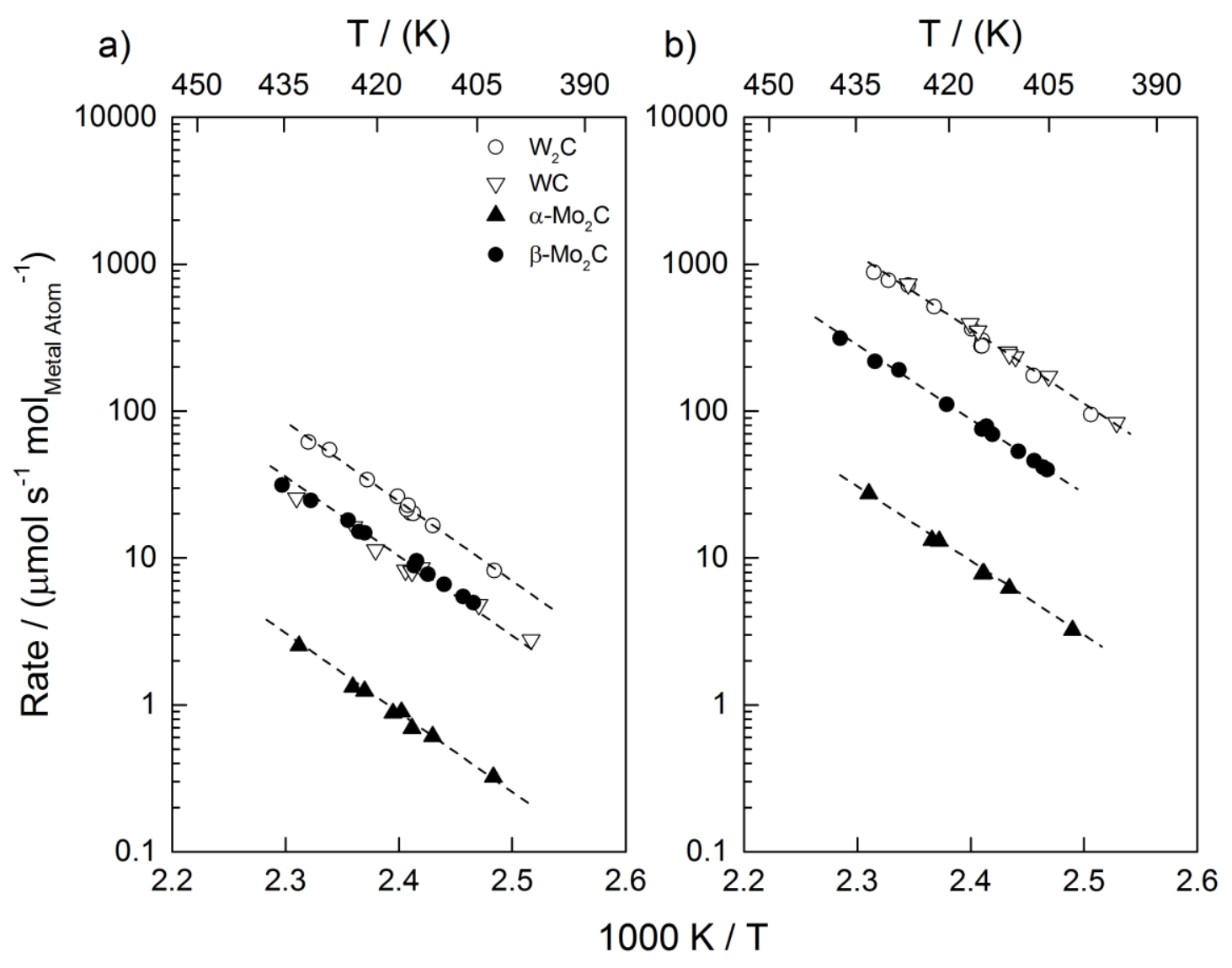

Figure 2. Propylene synthesis rates over interstitial carbide catalysts of tungsten and molybdenum, normalized per mole of $\mathrm{W}$ or $\mathrm{Mo}$, as a function of temperature (a) with no $\mathrm{O}_{2}$ co-feed, or (b) with $13 \mathrm{kPa} \mathrm{O}$ co-feed. $\mathrm{P}=114 \mathrm{kPa}, \mathrm{P}_{\mathrm{CH} 4}=4 \mathrm{kPa}$ (internal standard), $\mathrm{P}_{\mathrm{IPA}}=0.54$ or $1.1 \mathrm{kPa}$, balance $\mathrm{He}$ or Ar. Total gas flow rate of $1.83 \mathrm{~cm}^{3} \mathrm{~s}^{-1}$. Approximately $0.1 \mathrm{~g}$ of oxide precursor was loaded for each synthesis and subsequent reaction tests $\left(0.2 \mathrm{~g}\right.$ for $\left.\alpha-\mathrm{Mo}_{2} \mathrm{C}\right)$. Conversion varied from $0.1-20 \%$ for (a) and $0.9-$ $78 \%$ for (b). 


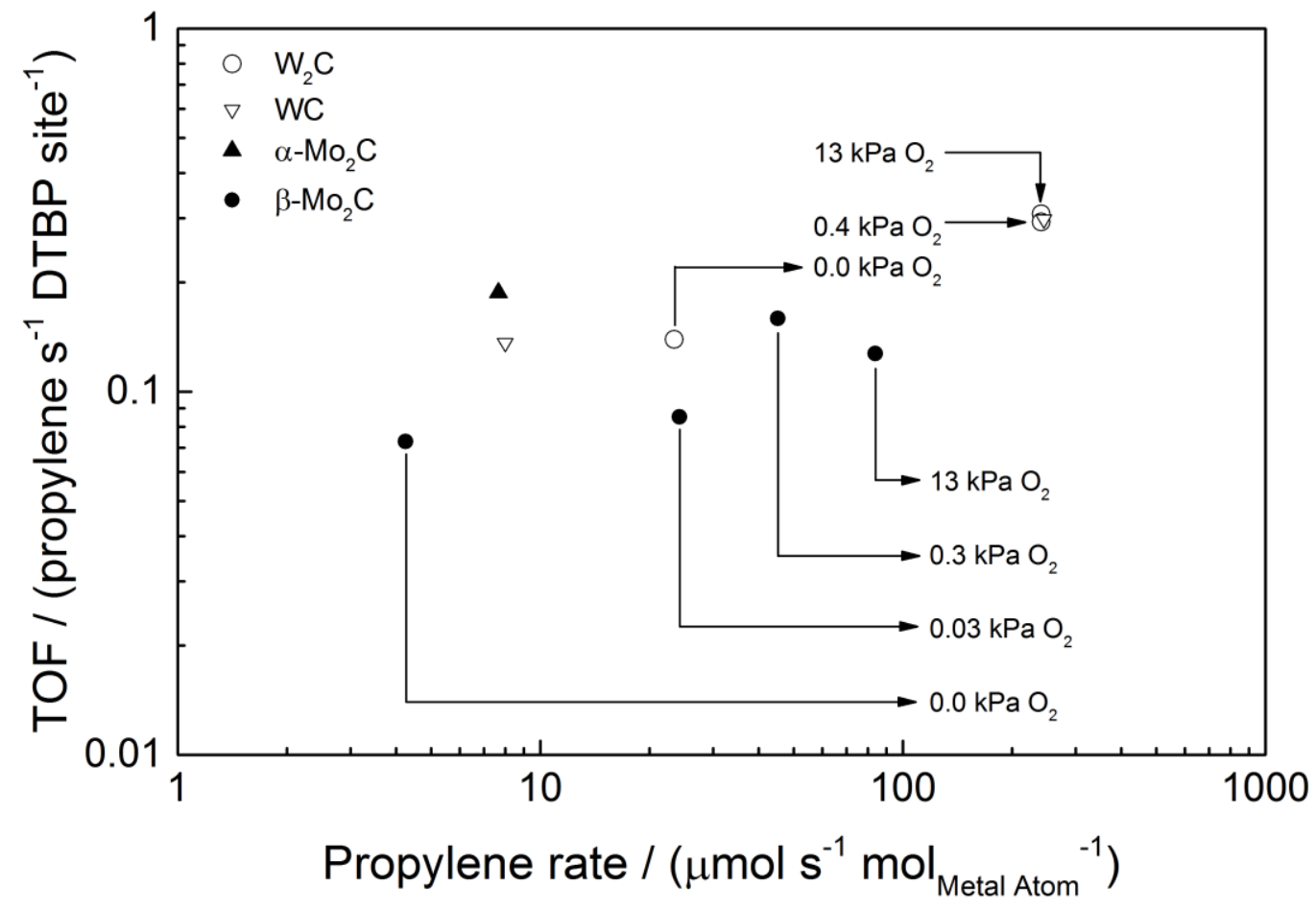

Figure 3. Propylene turnover frequency (TOF) as a function of propylene synthesis rate normalized by catalyst loading for carbides of $\mathrm{W}$ and Mo. TOF values are listed in Table 1 and were measured on the catalyst formulations used for IPA pressure and temperature variation experiments shown in Figures 1 and 2. TOF values with $\mathrm{O}_{2}$ co-feed pressures in between 0 and $13 \mathrm{kPa}$ are also plotted for $\beta-\mathrm{Mo}_{2} \mathrm{C}$ and $\mathrm{W}_{2} \mathrm{C}$. TOF was normalized using Brønsted acid site density measured by extrapolation of in situ DTBP titration experiments. $\mathrm{T}=415 \mathrm{~K}, \sim 0.1 \mathrm{~g}_{\text {cat }}$ of oxide precursor, $\mathrm{P}=114 \mathrm{kPa}, \mathrm{P}_{\mathrm{IPA}}=0.54$ or $1.1 \mathrm{kPa}$, $\mathrm{P}_{\mathrm{CH} 4}=4 \mathrm{kPa}$ (internal standard), balance $\mathrm{He}$, total gas flow rate of $1.83 \mathrm{~cm}^{3} \mathrm{~s}^{-1}$. 


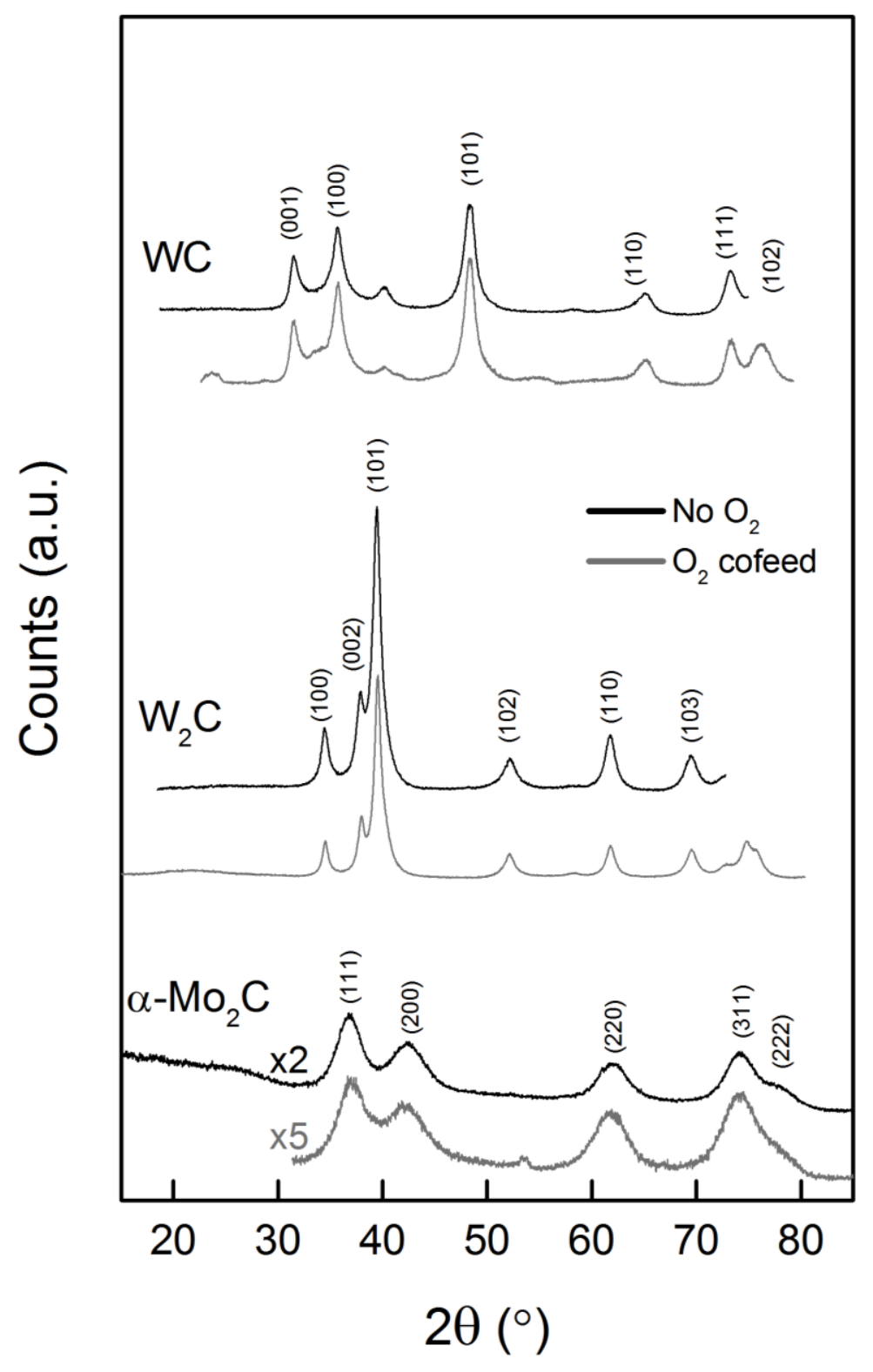

Figure 4. X-ray diffraction patterns of $\mathrm{WC}, \mathrm{W}_{2} \mathrm{C}$, and $\alpha-\mathrm{Mo}_{2} \mathrm{C}$ catalysts after reaction with or without $13 \mathrm{kPa} \mathrm{O}_{2}$ co-feed. Peak indices were obtained from the JCPDS database for WC (JCPDS PDF \# 01-089-2727), $\mathrm{W}_{2}$ C (JCPDS PDF \# 00-035-0776), and for $\alpha$ $\mathrm{Mo}_{2} \mathrm{C}$ (JCPDS PDF \# 03-065-0280). 
Table 1. Kinetic parameters of IPA dehydration over carbides of Mo and W with and without $\mathrm{O}_{2}$ co-feed. Tabulated numbers were obtained from data plotted in Figures 1, 2, and 3.

\begin{tabular}{|c|c|c|c|c|c|c|c|c|}
\hline & \multicolumn{4}{|c|}{$\mathrm{No}_{2} \mathrm{O}_{2}$ co-feed } & \multicolumn{4}{|c|}{$13 \mathrm{kPaO}_{2}$ co-feed } \\
\hline & $\mathrm{E}_{\mathrm{a}}{ }^{1}$ & $\alpha^{2}$ & TOF $^{3}$ & $\begin{array}{c}\mathbf{L}^{4} \\
\left(/ 1 \mathbf{1} \times 10^{-5}\right)\end{array}$ & $\mathbf{E}_{\mathrm{a}}{ }^{1}$ & $\alpha^{2}$ & TOF $^{3}$ & $\begin{array}{c}\mathbf{L}^{4} \\
\left(/ 1 \times 10^{-5}\right)\end{array}$ \\
\hline $\mathbf{W}_{2} \mathbf{C}$ & $104 \pm 6$ & -0.05 & 0.14 & 17 & $100 \pm 7$ & 0.01 & 0.31 & 78 \\
\hline WC & $89 \pm 9$ & 0.06 & 0.14 & 6 & $98 \pm 4$ & 0.11 & 0.30 & 82 \\
\hline$\alpha-\mathbf{M o}_{2} \mathbf{C}$ & $99 \pm 8$ & 0.08 & - & - & $99 \pm 5$ & 0.02 & 0.19 & 4 \\
\hline$\beta-\mathbf{M o}_{2} \mathbf{C}$ & $92 \pm 4$ & -0.02 & 0.07 & 6 & $94 \pm 3$ & 0.05 & 0.13 & 66 \\
\hline
\end{tabular}

${ }^{1}$ Activation energy in units of $\mathrm{kJ} \mathrm{mol}^{-1}$

${ }^{2}$ IPA partial pressure dependence on propylene formation rate $\left(\mathrm{r}=\mathrm{kP}_{\mathrm{IPA}}{ }^{\alpha}\right)$

${ }^{3}$ Propylene turnover frequency with units of (propylene $\mathrm{s}^{-1}$ DTBP site $^{-1}$ )

${ }^{4}$ Brønsted acid site density, as calculated by DTBP uptake extrapolated to titrate dehydration rates completely, normalized per bulk metal atom (Mo or $\mathrm{W}$ ) 


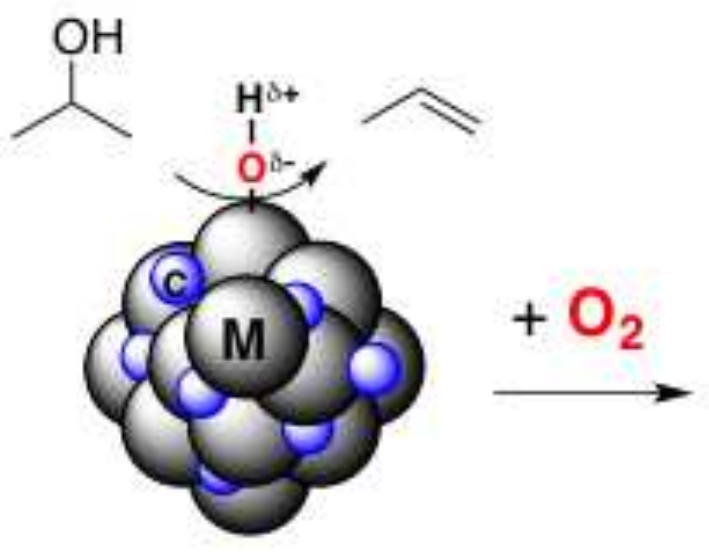

Metal carbide ( $\mathrm{M}=\mathrm{Mo}, \mathrm{W})$

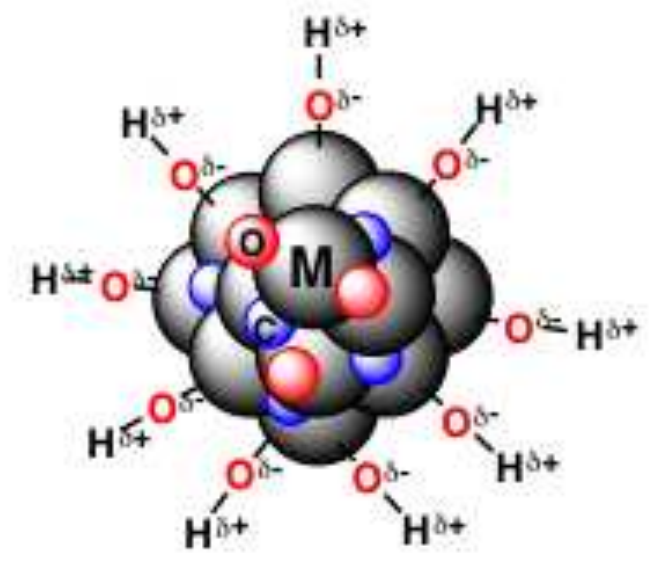

Oxygen-modified metal carbide

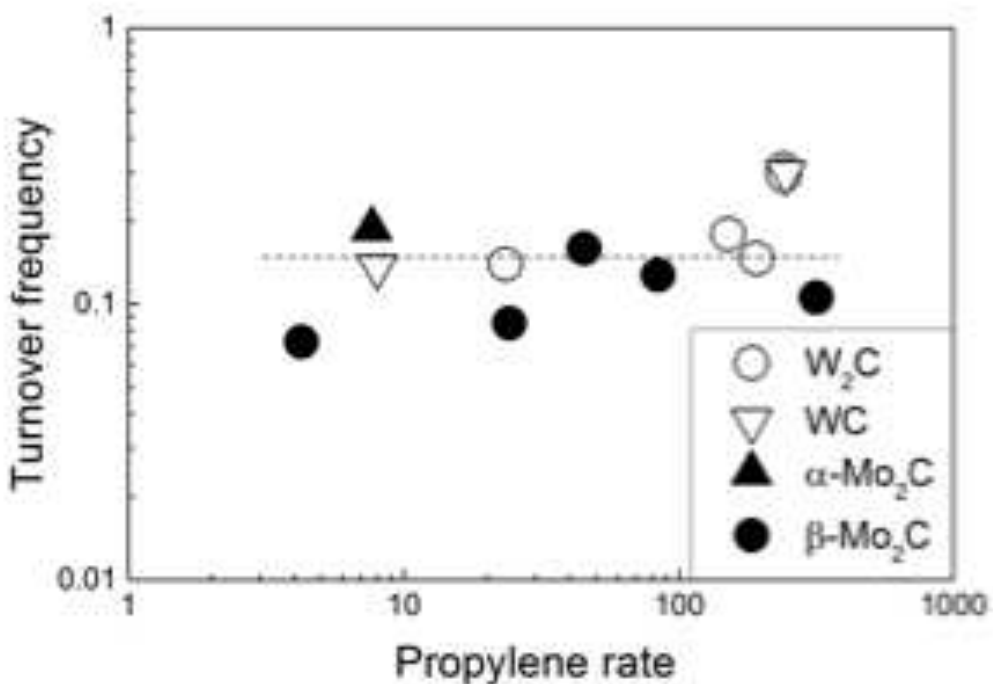

